\title{
Study on Deterioration Mechanism and Prevention and Curing Techniques of an RC Bunker
}

\author{
Henglin Lv, Haijian Xie, and Shuchun Zhou \\ School of Architecture and Civil Engineering, China University of Mining \& Technology \\ Jiangsu Key Laboratory of Environmental Impact and Structural Safety in Engineering \\ Sun Lei \\ School of Architecture and Civil Engineering, China University of Mining \& Technology
}

\begin{abstract}
In the coal mining industrial environment, the materials of RC bunkers suffer from serious aging problems. The cracking and deterioration of concrete and the corrosion of steel reinforcement lead to a degeneration of structural performance and a decline of structural reliability. In this paper, based on on-site detection and coal mining ground industrial environment, the deterioration characteristics of RC bunkers were tested. The investigation involved the apparent characteristics, carbonized depth, compression strength of concrete, reinforcement distribution and cover thickness, corrosion rate and mechanical properties of reinforcement, decline degree of bunkers, and so on. Then a design review check was done. Combined with the above information, the cause and mechanisms of cracking and damage of the structure were studied; finally, the problems of RC bunkers were targeted and improved. The work provides a reference method for repairing a deteriorated RC bunker in an aggressive service environment.
\end{abstract}

Keywords: RC bunker, deterioration, mechanism, prevention and curing techniques.

\section{INTRODUCTION}

The service environment of bunkers in coal mines mainly include hostile natural environments as well as complex technological and mechanical environments (Lv, Ma, \& Zhou, 2009; Song, Lu, Zhou, \& Wu, 2008; Tian, Lv, \& Liu, 2008). With prolonged service of an $\mathrm{RC}$ bunker, its materials get damaged and degraded, and different parts appear with different degrees of damage and cracking along the reinforcement, resulting in degradation in performance and decline in reliability. In April 2008, due to insufficient durability, an RC bunker in Xuzhou with insufficient bearing capacity of the whole structure collapsed, causing huge economic loss and casualties (Lv et al., 2009). Therefore, knowledge of the RC bunker fracture mechanism and research on its prevention and control technology are imperative. It is of great significance to extend the service life of structures and prevent the occurrence of major accidents.

\section{COAL MINING GROUND INDUSTRIAL ENVIRONMENT}

\subsection{Severe natural environment}

Through on-site inspection and monitoring of the natural environment of coal mines, we found that the environment in which the RC bunkers are located contains many corrosive gases such as $\mathrm{CO}_{2}, \mathrm{H}_{2} \mathrm{~S}$,
$\mathrm{HCl}, \mathrm{SO}_{2}, \mathrm{Cl}_{2}$, and so on. The content of $\mathrm{CO}_{2}$ at the inner frame part under the bunker was 384-442 ppm, and outside the bunker it was $356-410 \mathrm{ppm}$. The proportion of the other corrosive gaseous can be seen in Table 1. According to the Code for Anticorrosion Design of Industrial Constructions, the corrosion due to the gaseous environment of the RC bunker can be rated as severe.

Table 1. Test results of gaseous medium content (unit: $\mathrm{mg} / \mathrm{m}^{3}$ ).

\begin{tabular}{lccccc}
\hline Position & $\mathrm{CO}_{2}$ & $\mathbf{H C l}$ & $\mathrm{Cl}_{2}$ & $\mathbf{S O}_{2}$ & $\mathrm{NO}_{\mathbf{x}}$ \\
\hline Inside the bunker & 367.19 & 1.18 & 3.95 & 0.04 & 0.77 \\
Outside the bunker & 332.31 & 0.85 & 3.93 & 0.04 & 0.66 \\
\hline
\end{tabular}

Concrete pavement solid objects contain small amounts of calcium and magnesium chlorides. They were examined and are listed in Table 2 . These levels are moderate compared to the corrosive ranking of the solid environment of the RC bunker.

Table 2. Test results of gaseous medium content (unit: mg/L).

\begin{tabular}{lcccc}
\hline Position & $\mathbf{C l}$ & $\mathbf{S O}_{4}^{2-}$ & $\mathbf{C a}^{2+}$ & $\mathbf{M g}^{2+}$ \\
\hline $\begin{array}{l}\text { Funnel dripping water } \\
\text { samples }\end{array}$ & 368.07 & 989.93 & 70.146 & 12.126 \\
\hline
\end{tabular}

The liquid medium contains chlorides, sulfates, and so on. The content of some corrosive ions can be seen in 
Table 3. It is moderate compared to the corrosive rank of the liquid environment of the RC bunker.

Table 3. Test results of gaseous medium content (unit: $\mathrm{mg} / \mathrm{g}$ ).

\begin{tabular}{lllccc}
\hline Position & $\mathrm{MgO}$ & $\mathrm{CaO}$ & $\mathrm{SiO}_{2}$ & $\mathrm{Fe}_{2} \mathrm{O}_{3}$ & $\mathrm{Al}_{2} \mathrm{O}_{3}$ \\
\hline In the bunker & 13.45 & 5.25 & 20.20 & 4.35 & 13.45 \\
\hline
\end{tabular}

At the same time, the environment alternates between wet and dry frequently.

\subsection{Mechanical and technological environment}

Because of the special production and storage needs of a coal bunker, the RC bunker has a special shape (Figures 1 and 2). The stress distribution is complicated, the displacement is difficult to control, and local stress concentration is present. The silo wall undergoes outward extension due to the horizontal pressure of the stored coal. Meanwhile, large transmission equipment is arranged at the top of the coal bunker. In addition to withstanding the weight and quality of the upper transmission equipment, the dynamic response under a dynamic load is more intense. Long-term vibration of concrete causes internal damage due to fatigue and affects the structural safety.

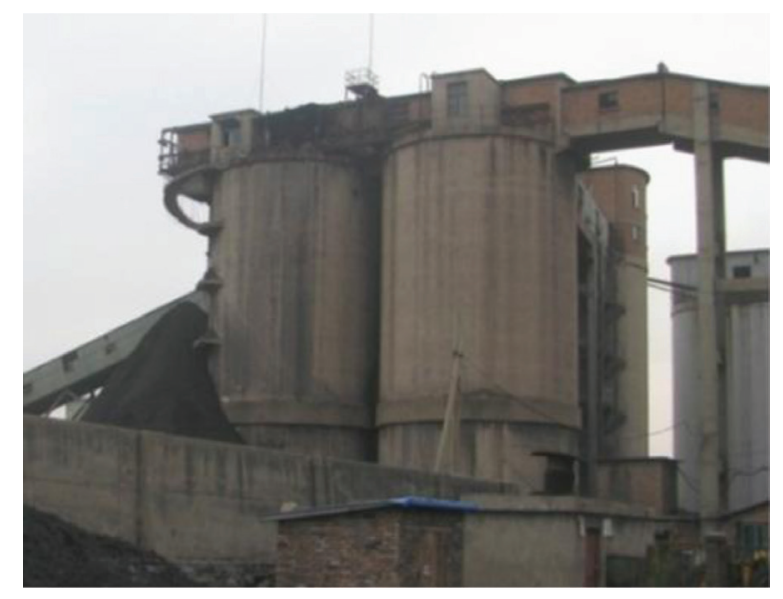

Figure 1. Panoramic view of the bunker.

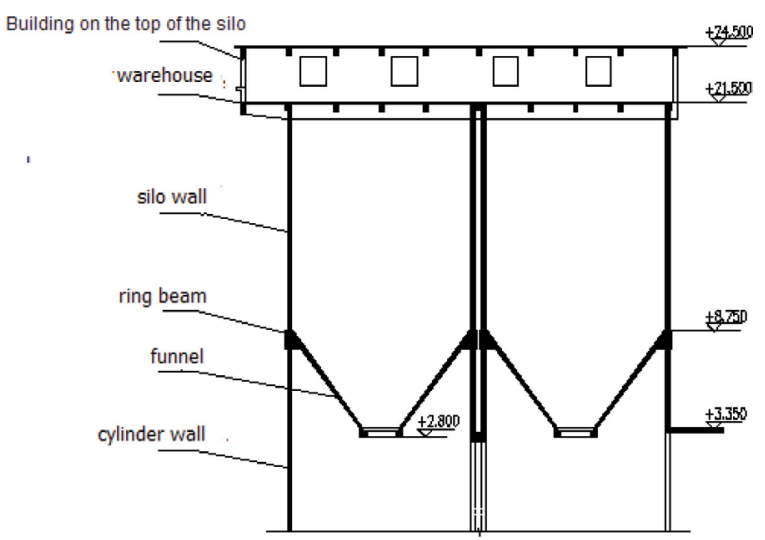

Figure 2. Profile of the bunker.

\section{DAMAGE AND DETERIORATION AND DETERIORATION CHARACTERISTICS OF RC BUNKER}

\subsection{Apparent characteristics}

A concrete surface gets corroded in the coal mining ground industrial environment. In part of the surface of the warehouse, the silo wall, the cylinder wall, and the funnel, cracks appear along the reinforcement, and some concrete is also seriously damaged. Reinforcement corrosion is serious, and a small amount of rust can start it. Sometimes, the cylinder wall is subjected to vehicle collision during transportation, causing component damage. Because of the presence of a ring beam that protects the surface, there is no crack on the concrete surface. At the same time, at certain times, coal is often stacked in a high pile, which causes a certain lateral extension to the silo wall. The ladder gets completely damaged. Part of the appearance is shown in Figures 3 and 4.

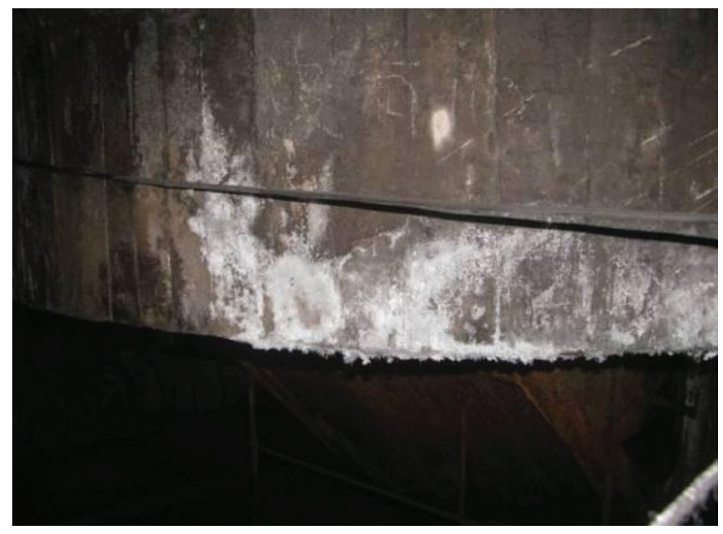

Figure 3. Funnel concrete surface with corrosive medium.

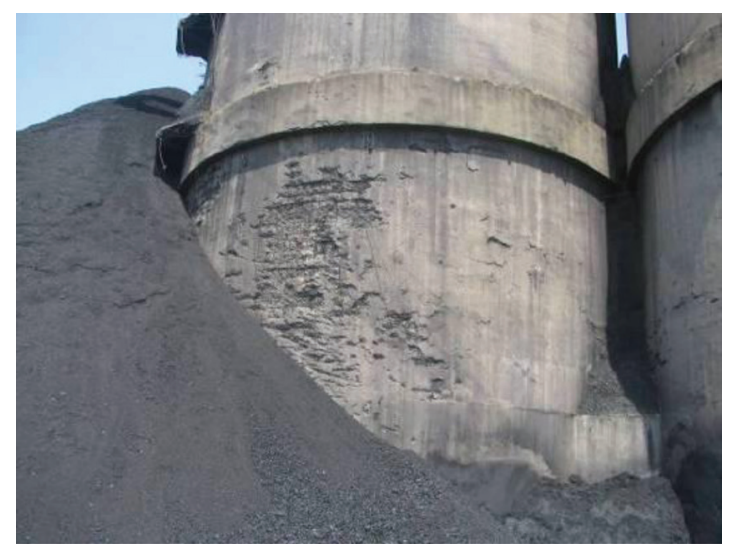

Figure 4. Damaged concrete wall of the bowl.

\subsection{Concrete carbonation depth}

By applying an alcohol solution containing $1 \%$ phenolphthalein to the concrete surface, a red border appears at the interface of concrete neutralization 
(Lv, Song, \& Zhao, 2008; Lv, Zhou, \& Wu, 2007; Wu, Yuan, \& Li, 2007; Zhao, Lv, \& Zhou, 2008). Details of the test can be seen in Table 4.

The average concrete carbonation depth is $42.8 \mathrm{~mm}$, which is deeper than the originally designed concrete cover.

\subsection{Concrete compression strength}

We adopt the resilience law to test the concrete compression strength of the silo wall, ring beam, hopper, and cylinder wall. The test was carried out with the core drilling method. Details of the test can also be seen in Table 4.

Table 4. Test results of concrete carbonation depth and strength.

\begin{tabular}{llcc}
\hline Position & Appearance condition & $\begin{array}{c}\text { Average } \\
\text { depth of } \\
\text { carbonation } \\
(\mathbf{m m})\end{array}$ & $\begin{array}{c}\text { Estimated } \\
\text { concrete } \\
\text { strength } \\
\text { (MPa) }\end{array}$ \\
\hline Warehouse & $\begin{array}{l}\text { A small amount of } \\
\text { concrete is damaged, } \\
\text { reinforcement exposure }\end{array}$ & - & - \\
Silo wall & $\begin{array}{l}\text { Some concrete is } \\
\text { damaged, reinforcement } \\
\text { exposure, serious } \\
\text { reinforcement corrosion }\end{array}$ & 40.4 & 20.0 \\
Ring beam & $\begin{array}{l}\text { The surface layer of } \\
\text { concrete undamaged }\end{array}$ & 25.1 & 21.7 \\
Funnel & $\begin{array}{l}\text { A small amount of } \\
\text { concrete is damaged, } \\
\text { reinforcement exposure, } \\
\text { reinforcement corrosion } \\
\text { Some concrete is } \\
\text { damaged, reinforcement } \\
\text { exposure, serious } \\
\text { reinforcement corrosion }\end{array}$ & & \\
Cylinder & 64.4 & 21.5 \\
wall & & & \\
\hline
\end{tabular}

The result shows that the strength of concrete in the major components meets the requirements of the original design.

\subsection{Reinforcement distribution and thickness of protective cover}

A reinforcement detector was used to test the reinforcement distribution and thickness of the protective cover.

The result shows that the reinforcement diameter is in conformity with the original design. But some spacings of the bars do not tally with the drawing. Most of the concrete protective cover is lower than the requirements of the current code for the design of concrete structures (GB50010-2010, 2010).

\subsection{Reinforcement corrosion rate and mechanical properties}

We conducted a corrosion test on the transverse reinforcement of the silo wall and cylinder wall; in addition, we collected a small amount of transverse reinforcement from the area for mechanical testing in the laboratory. We used a Vernier caliper to measure the reduction in the reinforcement area to test the rusting and corrosion rate of the reinforcement. And we conducted a tensile experiment to test the mechanical properties of the reinforcement.

The result shows that the transverse reinforcement corrosion rate is relatively close, mainly between 12.95 and $15.73 \%$, the maximum being $19.18 \%$. The mechanical performance test on the reinforcement shows that in sampling part of the steel, the yield strength and ultimate tensile strength suffered a certain degree of decline, below the material requirements. Corroded reinforcement yield limit was not very obvious, and reinforcement elongation was small. This shows that the reinforcement had undergone obvious embrittlement.

\subsection{Overall tilt}

A theodolite was used to test the overall tilt of the bunker, and the test results are shown in Table 5.

The result shows that the bunker's overall tilt and tilt rate are small, and it can meet the requirements of the currently applicable specifications (GB501442008, 2008).

Table 5. The tilting test results.

\begin{tabular}{llccc}
\hline Position & Direction & $\begin{array}{c}\text { Offset } \\
\text { direction }\end{array}$ & $\begin{array}{c}\text { Offset } \\
(\mathbf{m m})\end{array}$ & $\begin{array}{c}\text { Tilt rate } \\
\mathbf{( \% )}\end{array}$ \\
\hline West bunker & East and west & East & 10.04 & 0.47 \\
East bunker & East and west & East & 22.47 & 1.05 \\
& North and south & South & 15.66 & 0.73 \\
\hline
\end{tabular}

\section{RESULT OF CHECKING CALCULATION}

\subsection{Method of checking calculation}

We used the actual situation for coal and the existing standards to check the measured results (GB500102010, 2010; GB50011-2010, 2010). Checking was done according to the relevant drawings and dimension modeling of the field testing location. We used the silo module of the PKPM structure design software for calculation and analysis.

\subsection{Selection of parameters}

The component and structural dimensions can be found in the project overview. Attached facilities and machinery were considered as dead load and live load, wind, and earthquake load were considered at the same time. The bunker was evaluated assuming it to be in the full state. A reduction factor was taken to account for the deteriorating concrete and capacity. This factor for the component material was taken as 1.0 , and for the adhesive it was taken as 0.7. 


\subsection{Interpretation of results}

Reinforcement of the warehouse, silo wall, ring beam, hopper, and cylinder wall did not meet the requirement of the current seismic code. Part of the results can be seen in Table 6.

\section{CAUSES AND MECHANISM OF CRACKING}

(1) The bunker was built in the 1960s and it was not designed from the point of view of durability; the concrete cover thickness was smaller than currently required, and it had no protective surface layer. In addition, the reinforcement had not been subjected to any special anti-rust treatment. Because the construction level was limited at that time, the construction of these special structures has a certain degree of difficulty. Consequently, there were some problems such as non-compacting concrete vibrators and the concrete surface with honeycomb and scale, and some parts had smaller thickness of the protective layer. Therefore, a variety of corrosive media easily penetrated the internal parts of the concrete.

(2) The coupling effect of the natural environment and the technological mechanical environment at the mine surface gives rise to physical and chemical effects, damaging and deteriorating concrete (Lv, Wu, \& Zhou, 2010). Physical effects usually include alternation of drying and wetting, freeze-thaw cycles, etc., and chemical effects include acid erosion, sulfate attack, neutralization function, etc.

In the process of alternation of drying and wetting cycles, with crystalline expansion of $\mathrm{Na}_{2} \mathrm{SO}_{4}$ and $\mathrm{MgSO}_{4}$ that had invaded the concrete but not resulted in chemical reaction, the surface layer of concrete will crack and lead to the reduction of strength. In addition, the internal part of concrete will become loose. The main types of freeze-thaw cycles are pure-water freeze-thaw cycles and salt-water freeze-thaw cycles.

When the relative humidity is greater than $75 \%$ in a chemical interaction, $\mathrm{HCl}$ and $\mathrm{Cl}_{2}$ will form highly corrosive acid mist and erode the concrete, and the concrete protective layer will be corroded, damaged, and flaked directly; weak acid mist that is formed by $\mathrm{CO}_{2}$ and other gases will make the concrete neutral. A corrosive liquid that is rich in $\mathrm{SO}_{4}{ }^{2-}$ will react with $\mathrm{Ca}(\mathrm{OH})_{2}$ by penetrating into the concrete and generating $\mathrm{CaSO}_{4} \cdot 2 \mathrm{H}_{2} \mathrm{O}$ or other crystals with a larger volume expansion, and the expansion force will result in the concrete cracking and making the internal microscopic cracks larger. $\mathrm{Cl}^{-}$will penetrate the concrete more easily through the larger cracks and take part in electrochemical reaction at the steel surface, resulting in corrosion and expansion of steel and making further invasion of salt solution easy, so that the reaction is repeated and eventually leads to the expansion of damage of the external concrete.

Some of the chemical reactions involved are as follows:

$$
\begin{aligned}
& \mathrm{HCl}: \quad \mathrm{CaCO}_{3}+2 \mathrm{HCl} \rightarrow \mathrm{CaCl}_{2}+\mathrm{CO}_{2} \uparrow \\
& \mathrm{Ca}(\mathrm{OH})_{2}+2 \mathrm{HCl} \rightarrow \mathrm{CaCl}_{2}+\mathrm{H}_{2} \mathrm{O} \\
& \mathrm{Cl}_{2}: \quad \mathrm{Cl}_{2}+2 \mathrm{H}_{2} \mathrm{O} \rightarrow 2 \mathrm{HCl}+\mathrm{O}_{2} \uparrow \\
& \mathrm{Ca}(\mathrm{OH})_{2}+2 \mathrm{HCl} \rightarrow \mathrm{CaCl}_{2}+2 \mathrm{H}_{2} \mathrm{O} \\
& \mathrm{SO}_{2}+2 \mathrm{Cl}_{2}+3 \mathrm{Ca}(\mathrm{OH})_{2}+2 \mathrm{H}_{2} \mathrm{O} \rightarrow \mathrm{CaSO}_{4} \downarrow \\
& +2 \mathrm{CaCl}_{2}+6 \mathrm{H}_{2} \mathrm{O} \\
& \mathrm{SO}_{2}: \mathrm{H}_{2} \mathrm{O}+\mathrm{SO}_{2} \rightarrow \mathrm{H}_{2} \mathrm{SO}_{3} \\
& \mathrm{Ca}(\mathrm{OH})_{2}+2 \mathrm{H}_{2} \mathrm{SO}_{3} \rightarrow \mathrm{Ca}\left(\mathrm{HSO}_{3}\right)_{2}+\mathrm{H}_{2} \mathrm{O} \\
& \mathrm{Ca}(\mathrm{OH})_{2}+\mathrm{H}_{2} \mathrm{SO}_{3} \rightarrow \mathrm{CaSO}_{3} \downarrow+2 \mathrm{H}_{2} \mathrm{O} \\
& \mathrm{NO}_{2}: \mathrm{H}_{2} \mathrm{O}+\mathrm{NO}_{2} \rightarrow \mathrm{H}_{2} \mathrm{NO}_{3} \\
& \mathrm{Ca}(\mathrm{OH})_{2}+2 \mathrm{H}_{2} \mathrm{NO}_{3} \rightarrow \mathrm{Ca}\left(\mathrm{NO}_{3}\right)_{2}+2 \mathrm{H}_{2} \mathrm{O} \\
& \mathrm{CO}_{2}: \mathrm{CO}_{2}+\mathrm{H}_{2} \mathrm{O} \rightarrow \mathrm{H}_{2} \mathrm{CO}_{3} \\
& \mathrm{Ca}(\mathrm{OH})_{2}+2 \mathrm{H}_{2} \mathrm{CO}_{3} \rightarrow \mathrm{Ca}\left(\mathrm{HCO}_{3}\right)_{2}+\mathrm{H}_{2} \mathrm{O} \\
& \mathrm{Ca}(\mathrm{OH})_{2}+\mathrm{H}_{2} \mathrm{CO}_{3} \rightarrow \mathrm{CaCO}_{3} \downarrow+2 \mathrm{H}_{2} \mathrm{O}
\end{aligned}
$$

\begin{tabular}{|c|c|c|c|c|}
\hline \multirow[t]{2}{*}{ Position } & \multicolumn{2}{|c|}{ Original design reinforcement $\left(\mathrm{mm}^{2}\right)$} & \multicolumn{2}{|c|}{ Checking reinforcement $\left(\mathrm{mm}^{2}\right)$} \\
\hline & $\begin{array}{l}\text { Transverse/ring } \\
\text { directions }\end{array}$ & $\begin{array}{l}\text { Longitudinal direction/ } \\
\text { radial direction }\end{array}$ & $\begin{array}{c}\text { Transverse/ring } \\
\text { directions }\end{array}$ & $\begin{array}{l}\text { Longitudinal direction/ } \\
\text { radial direction }\end{array}$ \\
\hline Warehouse & 188 & 188 & 335 & 335 \\
\hline Silo wall & 942 & 471 & 1004 & 707 \\
\hline Ring beam & $\begin{array}{l}1953 \text { (longitudinal } \\
\text { reinforcement) }\end{array}$ & 402 (stirrups) & $\begin{array}{l}2453 \text { (longitudinal } \\
\text { reinforcement) }\end{array}$ & 542 (stirrups) \\
\hline Funnel & 3215 & 3617 & 3385 & 3927 \\
\hline Cylinder wall & 942 & 571 & 1005 & 707 \\
\hline
\end{tabular}

(3) The degrees of concrete deterioration and reinforcement corrosion have a great effect on the bondability between the reinforcement and concrete. In the early stages, concrete is compact and its porosity is low. There is increased friction between the concrete aggregates, thereby increasing adhesion. Along with the increase in the degree of concrete

Table 6. Comparison of the original design and calculation results. 
deterioration, the concrete becomes loose, the chemical adhesion between the concrete gel and the surface of the reinforcement decreases, and the friction between the rusty reinforcement and the surface of deteriorated concrete decreases, thereby resulting in poor adhesion between the reinforcement and concrete. In the early stage of rusting of the reinforcement, a new product will be created that makes the adhesive surface more compressive. However, with increasing steel corrosion, the new product expands and some cracks appear at the concrete around the reinforcement in the absence of radial component of deteriorated concrete, thereby affecting the adhesive performance between the rusted reinforcement and the deteriorated concrete.

(4) Thereare four main factors causing the deterioration of various components of silos: (a) the damage leads to a decrease of the some functions, such as compressive resistance and splitting tensile strength; (b) the rusty reinforcement creates corrosive cracks, which lead to the spalling of the concrete component and the loss of partial section size; (c) the section loss of corroded reinforcement causes the reduction of yield strength and ultimate tensile strength and thus the carrying capacity; (d) the degradation affects interfacial bonding performance between the corroded reinforcement and concrete. Factor (a) is mainly due to the effects of the physical and chemical environmental, whereas factors (b)-(d) are primarily caused by the corrosion of the reinforcement in concrete.

(5) The silo is a special structure (Yin, He, \& Liu, 2010; Zhong, 1994) in terms of the theoretical design (GB50144-2008, 2008; GB50011-2010, 2010; Lv et al., 2010), and in the actual situation (Zhong, 1994) we find that the intersecting parts of the silo wall and ring beam are the most likely to be destroyed. The silo wall is a thin structure, and when the silo is full one has to consider the lateral horizontal pressure on the silo wall due to the coal and the vertical pressure on the top of the silo due to the belt corridor and transmission equipment. It should also withstand the continuous power effects due to the belt of the conveyor under the action of a variety of external forces. Therefore, the stress situation of the silo wall is somewhat complex. But we can draw a conclusion that the lower stress of silo wall is greatest (the bunker belonging shallow silo by calculating, generally vertical pressure is small and don't have to configure the vertical reinforcement, it requires to configure according to the structure thin-walled members), the relative displacement of silo wall will decrease gradually along with the increase of elevation, displacement of a larger area appears about a third of the range at the bottom of the silo wall. For these reasons, the silo wall shows the "bulging belly" phenomenon and $p-\Delta$ effect. Especially, at the intersecting parts of the silo wall and ring beam, microfractures tend to appear and develop easily, which makes the material more likely to degrade than other parts of the site and easily break from the area.

(6) The vibration of the upper bunker belt conveyor load and lower timing cycle loading and unloading coal have an impact on the bunker materials, components, and overall structure, and cause a sustained fatigue damage. The weak parts of the structure first develop microcracks, which grow with the passage of time, and various corrosive media in the atmosphere will enter the concrete and corrode the internal material.

(7) The bunker lacks timely maintenance. Because of the need for ensuring the economic benefits of coal mines and taking into account the bunker's special functions and its own characteristics, various bunker components after deterioration cannot get timely maintenance and handling, and long-term quantitative changes cause qualitative changes, leading to insufficient capacity.

\section{PREVENTION AND CURING TECHNOLOGY}

(1) After applying anti-rust treatment for the internal reinforcement of all kinds of components which need to be repaired, we need to adopt a polymer, a modified cement mortar, or concrete to repair the original concrete components.

(2) For the warehouse and funnel, we adopt the method of pasting carbon-fiber-reinforced polymer (CFRP) for the reinforcement, applying prestressed steel strand-polymer mortar to reinforce the silo wall, pasting CFRP or section enlargement for reinforcement of the ring beam, and increasing the section or changing the loading for reinforcement of the cylinder wall.

(3) Components that have been adopted for the application of CFRP or section enlargement for reinforcement must have 20-mm-thick polymer mortar on the surface for maintenance. In the case of components that should be strengthened with prestressed steel strands, the polymer mortar coating must be 20 -mm-thick cement mortar on the surface for maintenance.

\section{MAIN CONCLUSIONS}

(1) Since the bunker was built in the 1960s, the reinforced concrete materials, components, and the structure have intrinsic defects because of the 
limited design and construction level at that time. This resulted in problems of safety, normal usability, and durability of the reinforced concrete bunker.

(2) In the coal mining industry, the natural environment is dangerous, corrosive gas concentration is higher, the corrosive liquid and solid media content is high, and dry and wet states alternate frequently; at the same time, the vibration load due to the silo's top belt transmission machine and the lower timing cycle of loading and unloading the coal cause constant fatigue damage to the bunker structure. For these reasons, if the bunker is not tested and maintained at regular intervals, these problems will lead to material deterioration, component damage, and long-term quantitative change, resulting in the lowering of the bearing capacity and decline in reliability. All the above are influenced by the reliability of the reinforced concrete materials and components.

(3) Because of the coupling effects of the inside and outside over a long time and considering the coal mine ground industrial environment and its own structure characteristics, microfracture is likely to develop easily in places where there is large stress distribution, which may result in damage and easy break-away of concrete. The relative displacement of the silo wall will decrease gradually with the increase of elevation; the displacement of a larger area appears about a third of that at the bottom of the silo wall. For these reasons, the silo wall will undergo the "bulging belly" phenomenon and the " $p-\Delta$ " effect. Especially, in the intersecting parts of silo wall and ring beam, microfractures tend to form and develop easily, making the material in these parts more likely to degrade and resulting in insufficient bearing capacity and decline in structural reliability.

(4) Prevention and cure of damage to the reinforced concrete bunker in the coal mining industrial environment must follow the principle of paying equal attention to the repair, reinforcement, and long-term maintenance. Reinforcement can be done in accordance with the requirements of the subsequent service life by formulating solutions to guarantee safety, but the solution should be economical, reasonable, and convenient for implementation. One can mainly adopt the method of pasting CFRP or steel plate for reinforcing parts of toroidal components and of increasing the section or changing the loading method for reinforcement for vertical components. At the same time, polymer mortar protection should be carried out to prevent further deterioration and to prolong the service life.

\section{ACKNOWLEDGMENTS}

Financial support for this work was provided by the Natural Science Foundation of the Jiangsu Province (BK2008128).

\section{REFERENCES}

GB50010-2010. (2010). Code for design of concrete structure [S], China Architecture \& Building Press. [In Chinese].

GB50011-2010. (2010). Code for seismic design of building[S], China Architecture \& Building Press. [In Chinese].

GB50144-2008. (2008). Standard for appraisal of reliability of industrial buildings and structures [S]. China Planning Press. [In Chinese].

Lv, H. L., Ma, Y., Zhou, S. C., et al. (2009).

Case study on the deterioration and collapse mechanism and curing technique of RC bunker in coal mine[C]. Proceedings of the 6th International Conference on Mining Science and Technology, Xuzhou (pp. 606-611).

Lv, H. L., Song, L., \& Zhao, C. M. (2008). Reliability detection and assessment of the RC major structure in the washery main plant of some colliery. Proceedings of International Conference on Distributed Computing Systems (pp. 10031007). Hangzhou: Zhejiang University Press.

Lv, H.-L., Wu, Y.-Z., \& Zhou, S.-C. (2010). Research on performance deterioration of reinforced concrete serving in colliery ground industrial environment. Concrete, 10, 37-40. [In Chinese].

Lv, H. L., Zhou, S. C., \& Wu, Y. Z. (2007). Study on deterioration mechanism and prevention and cure technology of RC structures in coal mining surface industrial environment. Proceedings of the 1st Cross-Strait Concrete Technology Workshop, Keelung, Taiwan. [In Chinese].

Song, L., Lu, H. L., Zhou, S. C., \& Wu, Y. Z. (2008). Reliability detection and appraisement of a bunker in a coal mine. Proceedings of the 7th National Conference on Durability of Concrete Structures, Yichang, China, Vol. 10, pp. 483-488. [In Chinese].

Tian, G.-H., Lv, H.-L., \& Liu, W. (2008). Study on fracture mechanism of RC structures in colliery environment. Journal of Xuzhou Institute of Architectural Technology, 8(2), 16-18. [In Chinese].

Wu, Q., Yuan, Y. S., \& Li, J. Y. (2007). Research on structural behavior's deterioration of corroded reinforced concrete beams under man-made climate. Journal of China University of Mining and Technology, 36(4), 441-445.

Yin, W.-X., He, P.-L., Liu, H.-Y. et al. (2010). Special structure [M]. China Electric Power Press. [In Chinese]. 
Zhao, C. M., Lv, T. F., \& Zhou, S. C. (2008). Reliability detection and assessment and reinforcement and maintenance measures of the RC structure in a certain washery main plant. Proceedings of the Second International Forum on Advances in
Structural Engineering (pp. 816-823). Dalian: China Architecture \& Building Press. [In Chinese]. Zhong, H.-Q. (1994). Special structure of coal mine [M]. Xu Zhou: China University of Mining and Technology Press. [In Chinese]. 